\title{
Fishing areas characterisation using the SIMOcean platform
}

\author{
Luisa Lamas ${ }^{1, *}$, Paulo B. Oliveira ${ }^{2}$, José P. Pinto ${ }^{1}$, Sara Almeida ${ }^{1}$, Ricardo Deus ${ }^{2}$, \\ António J. da Silva ${ }^{1}$ and Nuno Almeida ${ }^{3}$ \\ ${ }^{1}$ Instituto Hidrográfico, Rua das Trinas, 49, 1249-093 Lisboa, Portugal \\ 2 Instituto Português do Mar e Atmosfera I.P., Rua C do Aeroporto, 1749-077 Lisboa, Portugal \\ ${ }^{3}$ Deimos Engenharia SA, Av. D. João II, Lote 1.17.01, 10², Torre Zen, 1998-232 Lisboa, Portugal
}

Received 28 October 2016 / Accepted 3 May 2017

\begin{abstract}
In this study, the relationships between sea surface temperature (SST), chlorophyll-a (Chl-a) concentration and catch locations of sardine (Sardina pilchardus) and Atlantic chub mackerel (Scomber colias) were explored using satellite-derived SST and Chl-a together with fishing activity data for the southern and southwestern Portuguese coasts for the period January 2014 to December 2015. Chl-a and SST conditions linked with high catches differed between sardine and chub mackerel. On the southwestern Portuguese coast, sardine catches were highest for SST ranging from $16^{\circ} \mathrm{C}$ to $20^{\circ} \mathrm{C}$ and Chl-a concentration below $4 \mathrm{mg} \mathrm{m}^{-3}$, while high chub mackerel catches were associated with a broader range of SST values $\left(15-21{ }^{\circ} \mathrm{C}\right)$ and lower values of Chl-a $\left(<2 \mathrm{mg} \mathrm{m}^{-3}\right)$. On the south coast, both species had high catches for a broad range of SST conditions $\left(14-22^{\circ} \mathrm{C}\right.$ for sardine and $12-24^{\circ} \mathrm{C}$ for chub mackerel) and low Chl-a concentrations $\left(<2.5 \mathrm{mg} \mathrm{m}^{-3}\right.$ for sardine and $<1.5 \mathrm{mg} \mathrm{m}^{-3}$ for chub mackerel). Daily presence-absence maps based on these intervals are part of the System for Integrated Monitoring of the Ocean platform.
\end{abstract}

Keywords: Fisheries / Chlorophyll-a / Sea surface temperature

\section{Introduction}

Portugal has the largest exclusive economic zone in the European Union and the tenth largest in the world. Integrated management of Portuguese marine systems requires monitoring a wide range of interdependent areas. Data and information from different thematic areas, ranging from ocean and atmosphere state variables to higher level datasets describing human activities and related environmental, social and economic impacts need to be combined. Currently, these datasets are collected by a large number of public and private institutions for diverse purposes (e.g., monitoring, research, recreation and maritime surveillance) leading to dataset duplication, lack of common data and metadata standards, and the propagation of closed information systems with different implementation solutions. This lack of coordination and visibility hinders marine management, monitoring and surveillance capabilities, not only by making it more difficult to access, or even be aware of, the existence of certain datasets, but also by minimizing the ability to create added value products or services through dataset integration from different sources. Adopting an Open Data approach will bring significant benefits by reducing the cost of information exchange and data integration, promoting the extensive use of

\footnotetext{
* Corresponding author: luisa.lamas@hidrografico.pt
}

these data. The System for Integrated Monitoring of the Ocean project (SIMOcean) aims to improve the Portuguese marine management, monitoring and surveillance capabilities, by collating different datasets, including data for certain anthropogenic marine activities (vessel traffic, fishing records and oil spills), and environment variables (waves, currents and wind). The datasets currently scattered among different departments of the Instituto Português do Mar e Atmosfera, I.P. (IPMA) and Instituto Hidrográfico (IH), will be brought together to be exploited by three flagship value added services: (1) characterisation of fishing areas; (2) creation of a sea state index for harbour approaches; and (3) diagnostic of meteooceanographic fields (Almeida et al., 2016). The present work explains the methodology used in the implementation of the first demonstrative case, as well as the consistency of its outcomes, following Lamas et al. (2016).

Finding relations between fish distributions and oceanographic features is not trivial. Several studies have found correlations between surface currents, temperature, and phytoplankton concentrations and the spatio-temporal distribution of small pelagic fish (Castillo et al., 1996; NevárezMartínez et al., 2001; Borges et al., 2003; Solanki et al., 2005; Bakun, 2006; Lanz et al., 2009; Silva et al., 2009; Klemas, 2013). Borges et al. (2003) showed that strong upwelling favourable wind regimes led to unfavourable conditions for sardine (Sardina pilchardus) egg and larval survival off the Portuguese coast. Nevárez-Martínez et al. (2001) analyzed the 
Table 1. Description of datasets.

\begin{tabular}{llll}
\hline Data type & Spatial domain & Temporal resolution & Spatial resolution \\
\hline VMS & $36^{\circ}-39^{\circ} \mathrm{N} ; 7^{\circ}-11^{\circ} \mathrm{W}$ & $2 \mathrm{~h}$ & - \\
DPE & $36^{\circ}-39^{\circ} \mathrm{N} ; 7^{\circ}-11^{\circ} \mathrm{W}$ & ca. 1 day & - \\
Bathymetry & $32^{\circ}-46^{\circ} \mathrm{N} ; 1^{\circ}-16^{\circ} \mathrm{W}$ & - & $1.8 \mathrm{~km}$ \\
Chl-a & $36^{\circ}-42^{\circ} \mathrm{N} ; 6^{\circ}-15^{\circ} \mathrm{W}$ & 1 day & $1 \mathrm{~km}$ \\
SST & $36^{\circ}-42^{\circ} \mathrm{N} ; 6^{\circ}-15^{\circ} \mathrm{W}$ & $3 \mathrm{~h}$ & $2 \mathrm{~km}$ \\
\hline
\end{tabular}

distribution and abundance of Pacific sardine (Sardinops sagax) in the Gulf of California in relation to wind patterns and sea surface temperature (SST) and found that sardine abundance was highest in moderate upwelling conditions and SST between $19^{\circ} \mathrm{C}$ and $25^{\circ} \mathrm{C}$. Lanz et al. (2009) found that the abundance of Pacific sardine (Sardinops sagax caeruleus), thread herring (Opisthonema libertate) and Pacific mackerel (Scomber japonicus) in the Gulf of California was more related to chlorophyll-a (Chl-a) concentrations than to SST. Finally, dynamic oceanographic features, like convergence zones and thermal fronts were found to be indicative of possible fishing zones (Solanki et al., 2005; Bakun, 2006; Lanz et al., 2009). Until recently, in Portugal, the lack of continuous time series of complementary data hindered this type of comparative study. This has changed in 2014 with the implementation of electronic fishing logbooks for vessels over $12 \mathrm{~m}$, which provides continuous and more rigorous fishing activity data.

This study focuses on European pilchard (S. pilchardus) and Atlantic chub mackerel (Scomber colias) (hereinafter referred to as sardine and chub mackerel) due to their importance for the Portuguese economy. Decreasing stock abundance of sardine since 2008 led Portugal to introduce annual catch quota in 2010 (DGRM, 2013). Scientific evidence suggests that the sardine stock decrease was not caused solely by fishing, but that environmental variability also played a role (Borges et al., 2003; Silva et al., 2009). Geo-referenced fisheries catch data from the purse-seine fleet (vessels $>12 \mathrm{~m}$ ) were provided by the DireçãoGeral de Recursos Naturais, Segurança e Serviços Marítimos (DGRM) for the years of 2014 and 2015. These data were used together with satellite-derived SST and Chl-a concentration to study the spatio-temporal environmental characteristics of fishing areas. This study intends to be exploratory and does not take into consideration any prior knowledge on environmental preferences or stock sizes.

\section{Materials and methods}

\subsection{SIMOcean platform}

The SIMOcean system platform is a flexible framework able to communicate with the different information systems currently used by IPMA and IH. Its architecture provides full control to data and product providers to determine differentiated access permissions for each included dataset and is compatible with other information systems currently operational or under development at national or international levels. The software components are based on open source solutions, compliant with Open Geospatial Consortium standards (http://www.opengeospatial.org/standards) that derive from the SenSyF (http://www.sensyf.eu/framework.html) framework, a geospatial data handling framework optimized for big data with cloud based processing capabilities, developed by DEIMOS Engenharia. The system relies on Metadata Profile for the Sea developed by SNIM@R (http://snimar.pt) along with the European guidelines for Open Data. The user is able to download the datasets in netCDF format through a catalogue and a web visualization geoportal is currently being developed (more details in Almeida et al. (2016) and at www.simocean.pt).

\subsection{Study area and datasets}

This study focused on the southern part of the Portuguese coast and the period from January 2014 to December 2015. The study domain was divided into two areas: Western Area of Interest (WAOI): $37^{\circ}-39^{\circ} \mathrm{N} ; 10^{\circ}-8.6^{\circ} \mathrm{W}$, and Southern Area of Interest (SAOI): $36^{\circ}-37.2^{\circ} \mathrm{N} ; 10^{\circ}-7^{\circ} \mathrm{W}$. Five independent datasets covering the study areas were used (Table 1). Fishing activity data of the purse seine fleet (vessels $\geq 12 \mathrm{~m}$ ) were provided by DGRM and consist of two datasets: Vessel Monitoring System (VMS) data with vessel positions and electronic fishing logbooks (Diários de Pesca Electrónicos DPE) containing estimated catch per species for each fishing operation (purse seine set). Bathymetry was derived from a Digital Terrain Model (charted Low Water) of the IberianBiscay area $\left(32^{\circ}-46^{\circ} \mathrm{N} ; 16^{\circ}-1^{\circ} \mathrm{W}\right)$ with $1.8 \mathrm{~km}$ resolution, available at www.hidrografico.pt. The level-4 (L4) daily Optimal-Interpolation satellite-derived product of surface Chla concentration was downloaded from the Copernicus Marine Environment Monitoring Service (CMEMS) at $1 \mathrm{~km}$ resolution covering the Iberia-Biscay-Ireland Regional Seas. SST data was also downloaded from CMEMS and consisted of a L4 multi-sensor three-hourly (day and night) satellite product with a $2 \mathrm{~km}$ horizontal resolution.

For each DPE log (purse seine set), the values of Chl-a, SST and bathymetry were retrieved using the nearest neighbour square difference method. The result is an integrated set where each individual estimated catch record is associated with those parameters.

\subsection{Fishing activity data}

Fishing activity data were prepared using several steps. In the first step all fishing operations outside the area of interest were removed. In the second step DPE logs were screened using VMS data since VMS positions are recorded automatically while DPE logs can be recorded manually. VMS records and DPE logs showed that, on average, each vessel performed 

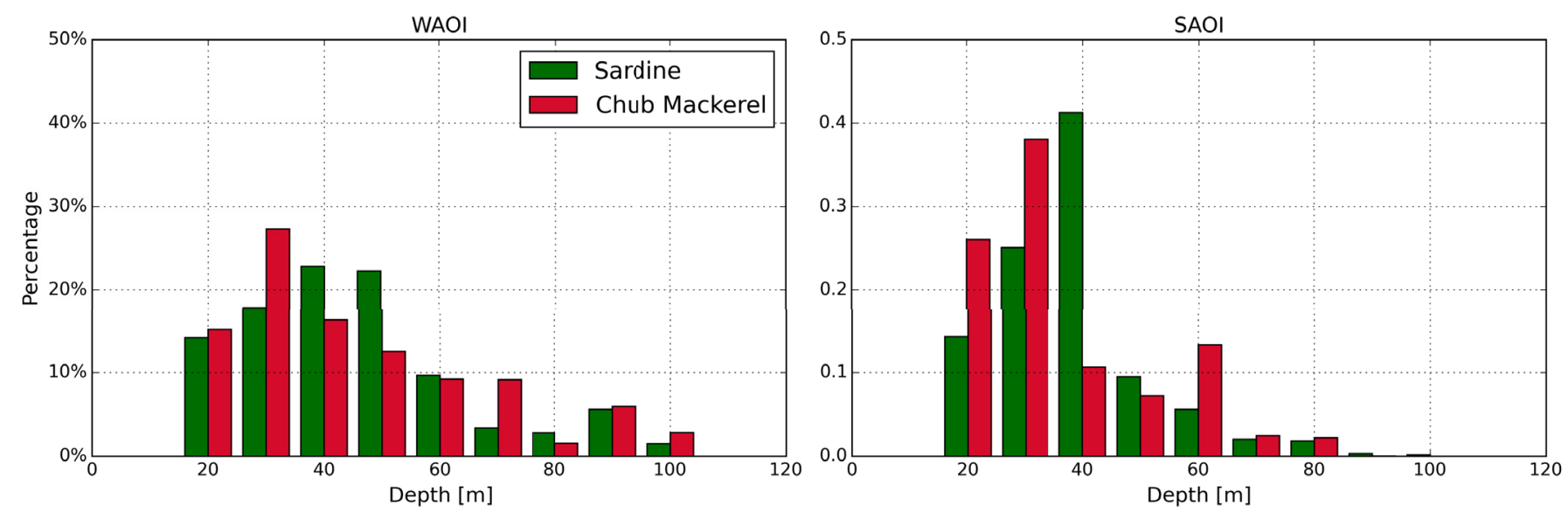

Fig. 1. Sardine and chub mackerel relative catches as a function of bottom depth for the Western Area of Interest (left) and the Southern Area of Interest (right) off the Portuguese coast.

one trip (a combination of consecutive VMS pings that started and ended at an harbour) per day with associated catch (DPE $\log$ ). Some discrepancies were found between the VMS and DPE datasets for some vessels. Some DPE logs were not in agreement with the position provided by the VMS. Some vessels consistently recorded the catch activity inside the harbour. Other vessels showed a large number of VMS trips but very few or null DPE logs. For these reasons, a quality control of the fishing activity data was necessary and DPE logs inconsistent with VMS data were removed. DPE logs corresponding to the following criteria were removed: (i) DPE logs registered in the harbour; (ii) DPE logs from vessels that showed less than 30\% relation between DPE logs and number of trips; (iii) fishing operations with positions inconsistent with VMS records and; (iv) DPE logs registered in regions shallower than $20 \mathrm{~m}$, since the purse seine fleet is not allowed to operate in this region.

Overall, $27 \%$ of the data were removed by this quality control process and 19 out of 49 vessels were excluded completely, since they did not have coherent fishing activity records.

\subsection{Statistical approach}

To analyse the spatio-temporal distributions of the fishing areas of each species, a catch-per-unit-effort (CPUE) index was defined as the average catch per fishing operation (Pereira et al., 2009):

$$
\mathrm{CPUE}=\frac{\sum_{i}^{n} C_{i}}{n}
$$

where $C_{i}$ is the catch of each species in fishing operation $i$ (in tons) and $n$ is the number of fishing operations with available logs. No information was available on net size, operation duration or the number of zero catch operations. Hence the total number of logs corresponding to positive fishing operations was used as effort.

For the CPUE calculation, each area was divided into rectangles. For the western area (WAOI), each rectangle corresponded to the total longitude interval $\left(10^{\circ}-8.6^{\circ} \mathrm{W}\right)$ and

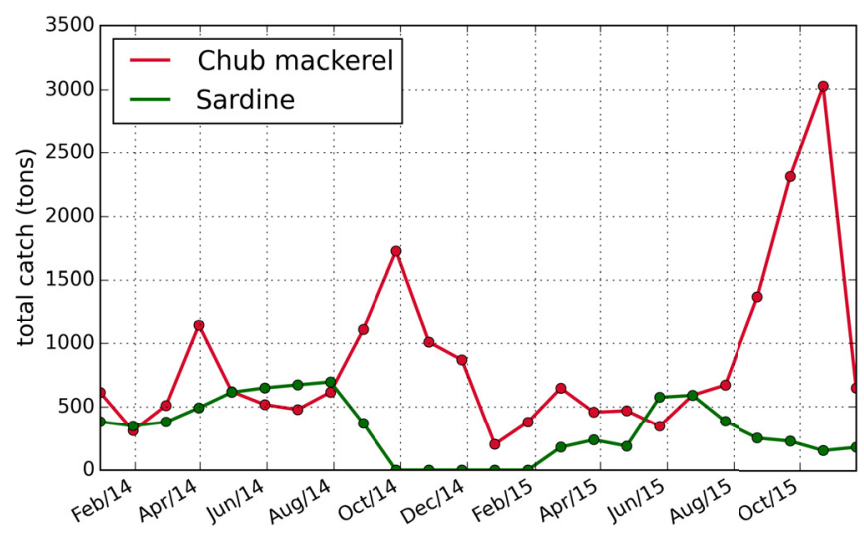

Fig. 2. Total monthly catches of chub mackerel (red) and sardine (green) for the two study areas off Portugal for 2014 and 2015.

$0.2^{\circ}$ in latitude. For the southern area (SAOI), each rectangle corresponded to the total latitude interval $\left(36^{\circ}-37.2^{\circ} \mathrm{N}\right)$ and $0.2^{\circ}$ in longitude. Weakly CPUE indices (Eq. (1)) were calculated for each rectangle for the study period January 2014 to December 2015.

A bivariate SST - Chl-a catch distribution was obtained by dividing SST values into $1^{\circ}$ intervals, from $12{ }^{\circ} \mathrm{C}$ to $26^{\circ} \mathrm{C}$, and Chl-a values into $0.5 \mathrm{mg} \mathrm{m}^{-3}$ intervals, from 0 to $7 \mathrm{mg} \mathrm{m}^{-3}$. For each SST-Chl-a class, and for each species, relative catch values were computed using all data from a given study area (WAOI and SAOI). Since more than $80 \%$ of catches of both species occurred between 20 and $60 \mathrm{~m}$ in both study areas (Fig. 1), only data between these depths were considered.

To study the spatial and temporal variability of sardine and chub mackerel catch locations in relation to Chl-a concentrations and SST conditions, an algorithm was developed to compute daily maps of Potential Fishing Areas (PFA) for each species. To produce such maps, three different datasets were considered: bathymetry data from $\mathrm{IH}$, daily Chl-a concentration fields from CMEMS and three-hourly SST fields, also from CMEMS.

All datasets were linearly interpolated to a common grid with resolution of $0.01^{\circ}$ (approximately $1 \mathrm{~km}$ ) for both areas, 


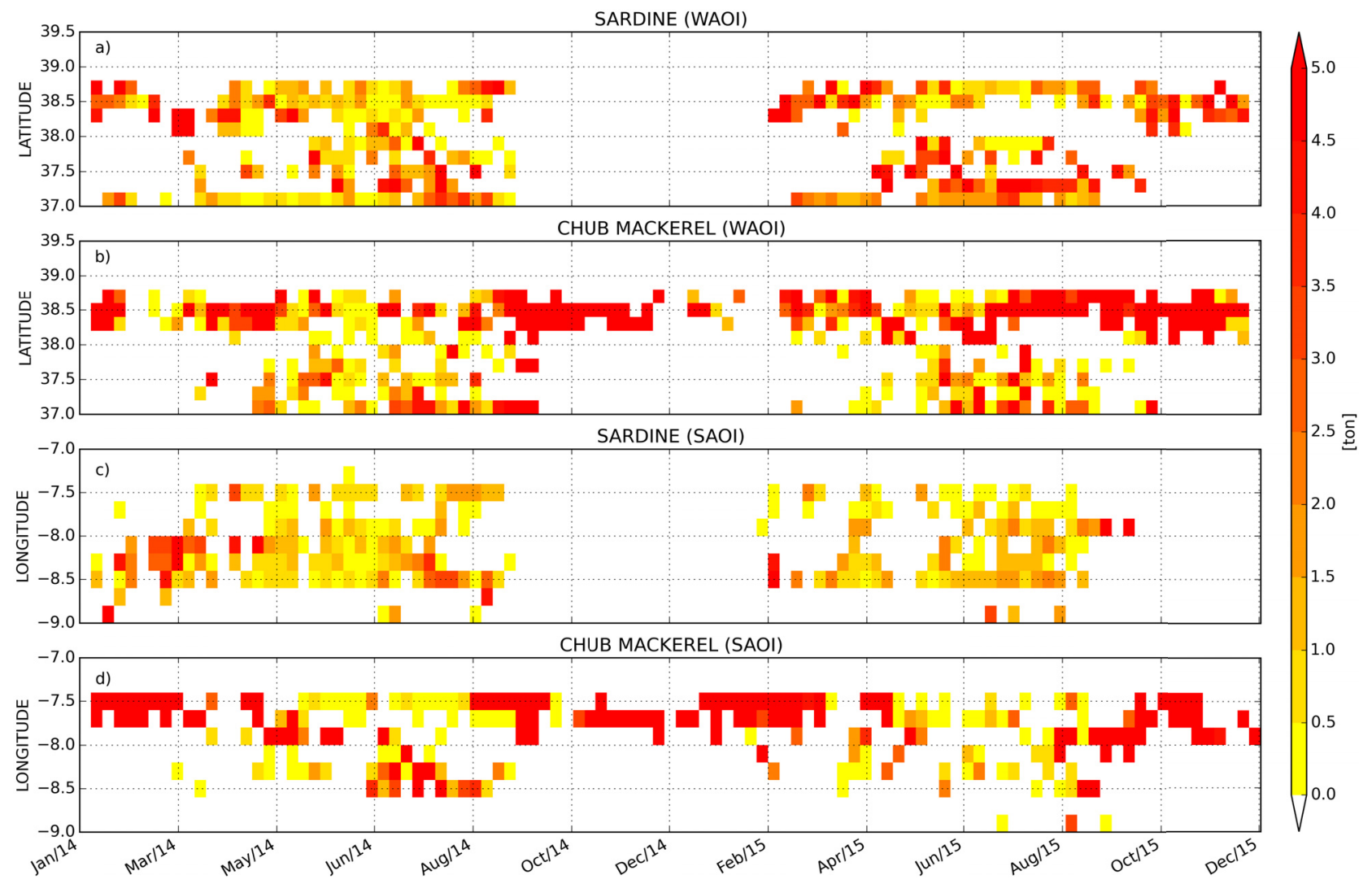

Fig. 3. Temporal and spatial distribution of weekly catch-per-unit-effort (CPUE) for sardine and chub mackerel for 2014 and 2015 for the WAOI (a and b) and SAOI (c and d).

and SST data were daily averaged to facilitate the point-bypoint inter-comparison. This resulted in three daily layers corresponding to SST, Chl-a and bathymetry data for each area (WAOI and SAOI).

A binary approach was used to mark the regions where the conditions corresponded to higher percentages of sardine or chub mackerel catches. An index was assigned based on the bivariate SST-Chl-a catch distributions. The index was computed using:

$$
\mathrm{PFA}=\min \left(i_{\mathrm{SST}}, i_{\mathrm{Chl}-\mathrm{a}}\right)
$$

where $i_{\mathrm{SST}}$ is the index for the SST and $i_{\text {Chl-a }}$ is the index for the Chl-a concentration. For each grid point, the index was equal to one if the pixel value was within the SST and Chl-a intervals identified from the bivariate distribution and zero otherwise. The result was a daily binary map, with $0.01^{\circ}$ resolution, where 1 represents regions of higher catches (PFA) and 0 for all the other regions. Only regions with depth between 20 and $60 \mathrm{~m}$ were considered for the PFA index.

\section{Results}

\subsection{Fishing area characterization}

According to DPE logs, chub mackerel and sardine were the first and second most caught species, with more fishing operations and bigger catches occurring during winter
(October-February) for the chub mackerel and during summer (May-August) for the sardine (Fig. 2). Sardine fishing was closed from October 2014 to February 2015.

The spatio-temporal distribution of sardine and mackerel catches was analysed using the CPUE index (Fig. 3). Overall, chub mackerel CPUE was higher than sardine CPUE and more productive during the last months of 2014 and 2015 (OctoberDecember), and for latitudes between $38^{\circ}$ and $39^{\circ} \mathrm{N}$ (Setubal Bay), although in summertime (May-September) chub mackerel CPUE was still high and extended to the southern part of the WAOI (Fig. 3b). CPUE for sardine was higher during summer (May-September) in more southern latitudes, although high values were also found in Setubal bay for January-March 2014, February-April 2015 and OctoberDecember 2015 (Fig. 3a). Contrary to summertime, during these periods, sardine CPUE was low or inexistent in the southern part of the area. In the SAOI, spatio-temporal differences between sardine and chub mackerel were more visible (Fig. $3 \mathrm{c}$ and d). Chub mackerel showed higher CPUE values for more eastern longitudes $\left(7.4^{\circ}-8^{\circ} \mathrm{W}\right)$ during wintertime (September through March). During summer, there were also high chub mackerel CPUE values in the eastern part of the area. Sardine showed higher CPUE values in more western longitudes $\left(8^{\circ}-9^{\circ} \mathrm{W}\right)$ during summertime, but high CPUE values were also present in the eastern part. For both areas, chub mackerel fishing was higher during the period when sardine fishing was closed (from October 2014 to February 2015). 

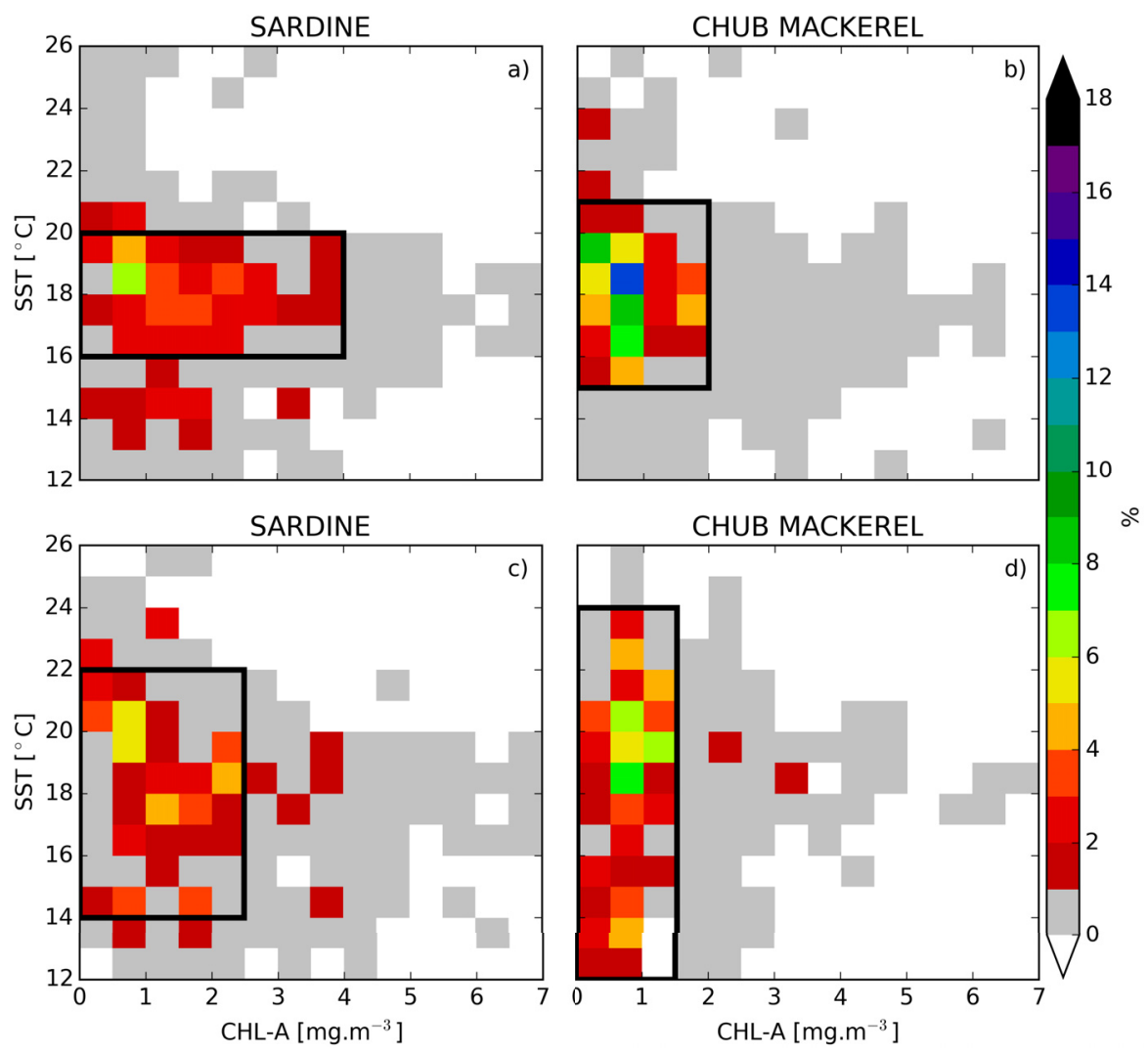

Fig. 4. Bivariate distributions of SST and Chl-a for sardine ((a) WAOI; (c) SAOI) and chub mackerel ((b) WAOI; (d) SAOI) catches for depths between 20 and $60 \mathrm{~m}$, for 2014-2015. The black rectangles identify SST and Chl-a ranges used in Figure 5.

Figure 4 shows bivariate SST-Chl-a catch distributions for sardine and mackerel. In the WAOI, there were clear differences between the bivariate distributions of sardine (Fig. 4a) and chub mackerel (Fig. 4b). Higher catches of chub mackerel occurred for lower values of Chl-a $\left(<2 \mathrm{mg} \mathrm{m}^{-3}\right)$ and for a broad SST interval $\left(15-21^{\circ} \mathrm{C}\right)$ while higher catches of sardine occurred for a larger Chl-a interval $\left(<4 \mathrm{mg} \mathrm{m}^{-3}\right)$ and for a smaller SST interval $\left(16-20^{\circ} \mathrm{C}\right)$. For the SAOI, higher catches of sardine were found for Chl-a concentrations below $2.5 \mathrm{mg} \mathrm{m}^{-3}$ and SST between 14 and $22^{\circ} \mathrm{C}$ (Fig. 4c), while chub mackerel catches were higher for Chl-a concentrations below $1.5 \mathrm{mg} \mathrm{m}^{-3}$ and SST between 12 and $24^{\circ} \mathrm{C}$ (Fig. 4d).

These SST and Chl-a intervals were used to map PFA for each species.

\subsection{Mapping PFA}

Examples of daily maps of PFA for 4 days in July 2015 are represented in Figure 5 for the WAOI and Figure 6 for the SAOI. These days were selected to represent the temporal and spatial variability of PFA for both species. In these figures only a few regions were marked as PFA and they varied between days. For the WAOI, the regions marked as PFA for sardine were usually located in the southern part of the area, from Cape Sines $\left(38^{\circ} \mathrm{N}\right)$ to Cape S. Vicente $\left(37^{\circ} \mathrm{N}\right)$, while PFA for chub mackerel were concentrated in the northern part, between $38^{\circ}$ and $39^{\circ} \mathrm{N}$ (Setubal Bay). In the SAOI, chub mackerel PFA were identified in the eastern part, while sardine PFA were concentrated in the western part. The spatial variability of PFA for both species was consistent with the spatial distribution of the CPUE index (Fig. 3).

\section{Discussion}

Several authors have studied the connection between small pelagic fish abundance (e.g., Pacific sardine, Pacific mackerel), SST and an upwelling index (Nevárez-Martínez et al., 2001; Borges et al., 2003) and Chl-a concentration (Lanz et al., 2009). Most studies found that fish abundance was typically more closely related to Chl-a than SST, suggesting that Chl-a can be used as an indicator of conditions favouring small pelagic fish. Chl-a content of the ocean's surface is a measure of phytoplankton (micro algae) which, in turn, is likely a good proxy for productive feeding grounds for most pelagic fish (Klemas, 2013). SST is likely to be less correlated with fish abundance, although some studies support the existence of preferable SST limits to sardine abundance, mainly connected with enrichment upwelling events indicated by high Chl-a and low SST (Nevárez-Martínez et al., 2001).

The identification of preferable environmental conditions of fishing activity areas requires a variety of data series with appropriate spatial and temporal coverage. Unfortunately, there are very few environmental data series giving adequate coverage of both spatial and temporal variability for fishing activities. In Portugal, the use of electronic fishing logbooks was enforced in 2014 for vessels $>12 \mathrm{~m}$, thus providing a more 

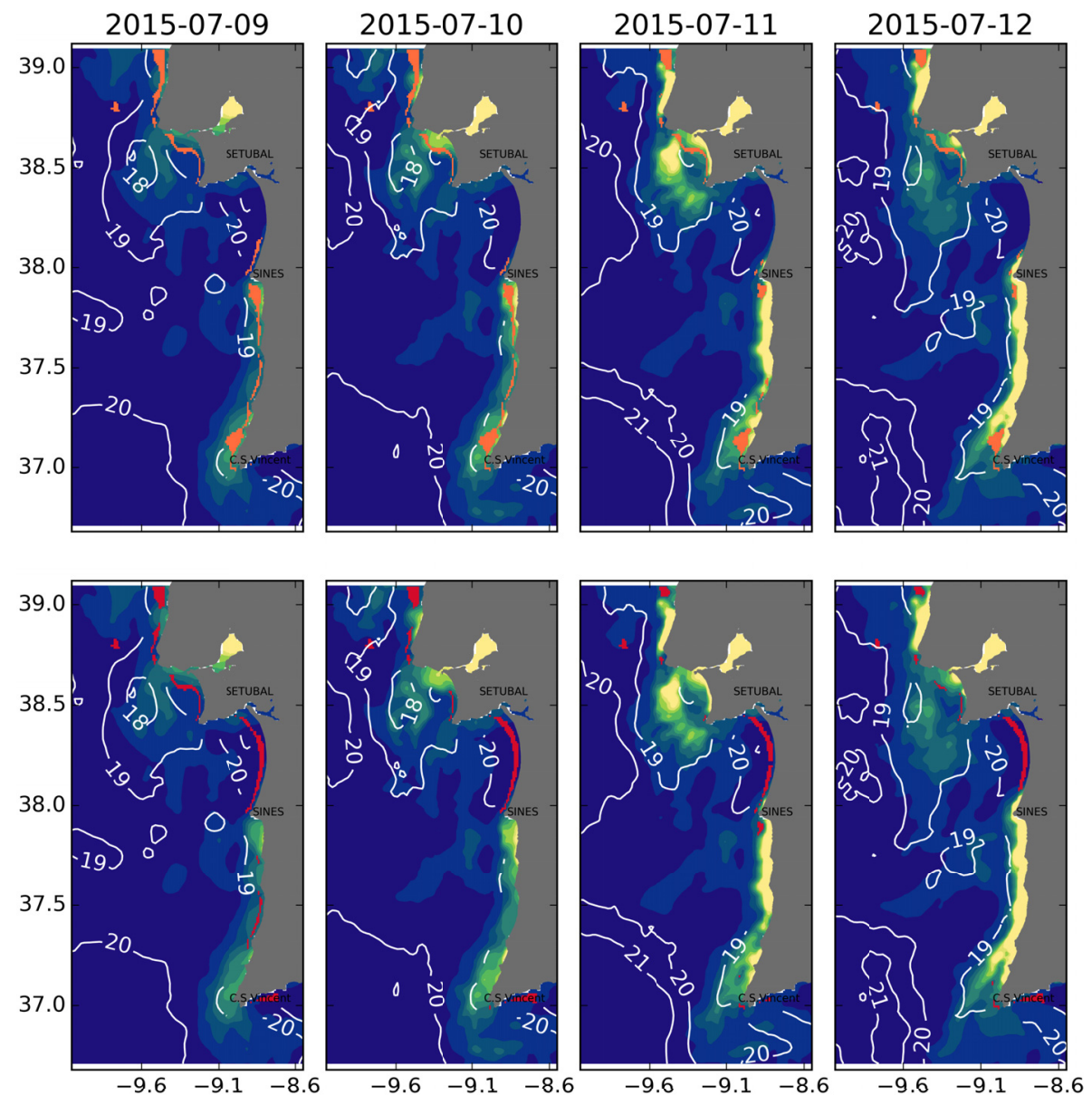

$\begin{array}{llllcc}0.0 & 0.5 & 1.0 & 1.5 & 2.0 & 2.5 \\ & & & & \text { CHL-A }\left[\mathrm{mg} \cdot \mathrm{m}^{-3}\right]\end{array}$

Fig. 5. Daily maps of potential fishing areas (PFA) showing in orange and red the regions where the daily oceanographic conditions during $9-12$ July 2015 corresponded to higher catches of sardine (top) and chub mackerel (bottom) for the WAOI, based on the bivariate SST-Chl-a catch distributions in Figure $4 \mathrm{a}$ and b. Chl-a concentrations as colour shadings and SST as isothermals (in ${ }^{\circ} \mathrm{C}$ ).

continuous and rigorous source of geo-referenced fishing activity data.

CPUE indices computed using fishing activity data from electronic logbooks for the years of 2014 and 2015 showed that chub mackerel had overall higher CPUE values than sardine (Fig. 3). However, fishing quotas that regulate the amount of sardine catch per year can limit these results, since sardine fishing will have to cease once a certain amount of catch is reached and may not reflect the real abundance of this species. For example, higher chub mackerel CPUE values were found in the Setubal Bay area during winter, coinciding with the period when sardine fishing was closed. For that reason, the results are not expected to show or predict the areas where sardine and chub mackerel are more abundant, since they only account for the time, location and estimated amounts of catch, and what were the Chl-a and SST conditions at that time, for that location. These results are simply intended to serve as a tool to identify areas where the environmental conditions are consistent with higher catches of sardine and chub mackerel.

In this study, the connection between SST, Chl-a concentration and high catch locations of sardine and chub mackerel were explored using freely-available satellite- derived products of SST and Chl-a from CMEMS together with fishing activity data for the period between January 2014 and December 2015 provided by DGRM. For this analysis, a cut-off depth of $60-\mathrm{m}$ was applied since more than $80 \%$ of both species catches occurred between 20 and 60-m depth. Differences between Chl-a and SST conditions related to higher sardine and chub mackerel catches are significant. For the WAOI, sardine catch was higher for SST ranging from $16^{\circ} \mathrm{C}$ to $20^{\circ} \mathrm{C}$ and $\mathrm{Chl}-\mathrm{a}$ concentration below $4 \mathrm{mg} \mathrm{m}^{-3}$, while chub mackerel showed higher catch concentrations for a broader SST interval $\left(15-21^{\circ} \mathrm{C}\right)$ and lower values of Chl-a $\left(<2 \mathrm{mg} \mathrm{m}^{-3}\right)$. For the SAOI, both species showed higher catches for broader SST intervals $\left(14-22^{\circ} \mathrm{C}\right.$ for sardine and $12-24^{\circ} \mathrm{C}$ for chub mackerel) and lower Chl-a concentration values $\left(<2.5 \mathrm{mg} \mathrm{m}^{-3}\right.$ for the sardine and $<1.5 \mathrm{mg} \mathrm{m}^{-3}$ for the chub mackerel). As seen in previous studies (Lanz et al., 2009), distributions in Figure 4 and PFA maps (Figs. 5 and 6) suggest that sardine and chub mackerel fishing areas are more influenced by Chl-a than SST. Further research and validation of the results with longer data series (ideally during years without fishing quotas and closed periods) is required for a more comprehensive analysis. 

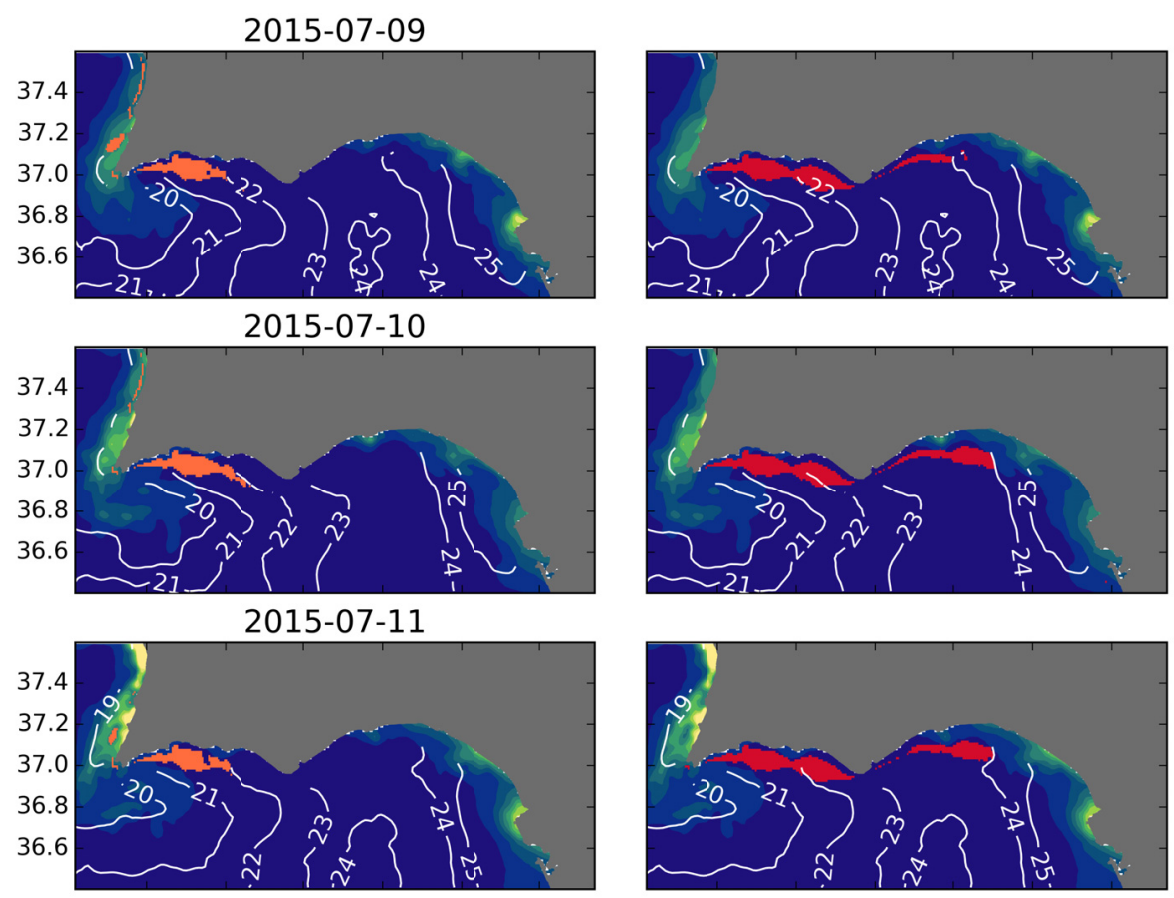

2015-07-12
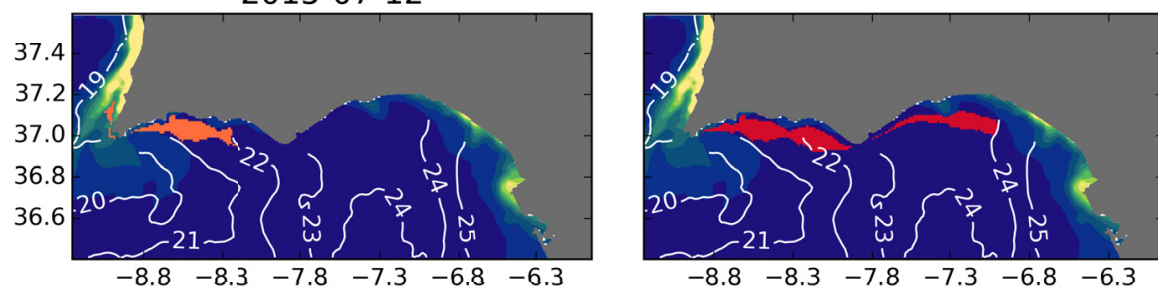

$\begin{array}{lllllllll}0.0 & 0.5 & 1.0 & 1.5 & \begin{array}{c}2.0 \\ \text { CHL-A }\left[\mathrm{mg} \cdot \mathrm{m}^{-3}\right]\end{array} & & \frac{1}{1} & & \frac{1}{1} \\ & & & & \end{array}$

Fig. 6. Daily maps of potential fishing areas (PFA) showing in orange and red the regions where the daily oceanographic conditions during $9-12$ July 2015 corresponded to higher catches of sardine (left) and chub mackerel (right) for the SAOI, based on the bivariate SST-Chl-a catch distributions in Figure 4c and d. Chl-a concentrations as colour shadings and SST as isothermals (in ${ }^{\circ} \mathrm{C}$ ).

The main results of this study are featured in the SIMOcean platform (Almeida et al., 2016) as a demonstrative case of the system's capabilities. In this particular service the end-user is able to visualize, in an integrated environment, areas where the conditions are equivalent to those of higher catches of chub mackerel or sardine together with several oceanographic features. The use of outputs from the HYCOM numerical model and sea surface currents measured hourly by the HF Radar network, both operated by IH and included in the SIMOcean platform, can be valuable to explore the connection between fishing areas and relevant oceanographic features, like surface currents, convergence zones (Bakun, 2006), thermal gradients (Lanz et al., 2009) and Chl-a residence time. Large inter-annual variations of upwelling can also impact small pelagic fish distribution (Borges et al., 2003) but longer fishing data series are necessary to explore this issue. This demonstrative case can be valuable to the fishing industry community, since it will bring an optimization of resources and investments from companies, helping a better management of fishing operations and marine resources.
Acknowledgements. Thanks are due to Direção-Geral de Recursos Naturais, Segurança e Serviços Marítimos for making available the VMS and DPE datasets, as well as for the enlightening discussions. This is a contribution to Project SIMOcean (System for Integrated Monitoring of the Ocean), Project PT02_Aviso5_0001, partly supported by the financial mechanism of the European Economic Area (EEA Grants).

\section{References}

Almeida N, Grosso N, Catarino N, et al. 2016. SIMOcean: Maritime Open Data and Services Platform for Portuguese institutions. In: 4as Jornadas de Engenharia Hidrográfica Proceed, pp. 389-392.

Bakun A. 2006. Fronts and eddies as key structures in the habitat of marine fish larvae: opportunity, adaptive response and competitive advantage. Sci Mar 70: 105-122.

Borges MF, Santos AMP, Crato N, Mendes H, Mota B. 2003. Sardine regime shifts off Portugal: a time series analysis of catches and wind conditions. Sci Mar 67: 235-244. 
Castillo J, Barbieri MA, Gonzalez A. 1996. Relationships between sea surface temperature, salinity, and pelagic fish distribution off northern Chile. ICES J Mar Sci 53: 139-146.

DGRM. 2013. Recursos da Pesca. Série Estatística, 25 A-B, 2012. Lisboa: Direção Geral dos Recursos Naturais, Segurança e Serviços Marítimos.

Klemas V. 2013. Fisheries applications of remote sensing: an overview. Fish Res 148: 124-136.

Lamas L, Oliveira PB, Pinto JP, et al. 2016. Fishing areas characterization using satellite, numerical model and HF radar data. In: 4as Jornadas de Engenharia Hidrográfica Proceed, pp. 175-178.

Lanz E, López-Martínez J, Nevárez-Martínez M, Dworak JA. 2009. Small pelagic fish catches in the Gulf of California associated with sea surface temperature and chlorophyll. CalCOFI Rep 50: 134-146.
Nevárez-Martínez MO, Lluch-Belda D, Cisneros-Mata MA, SantosMolina JP, Martínez-Zavala MA, Lluch-Cota SE. 2001. Distribution and abundance of the Pacific sardine (Sardinops sagax) in the Gulf of California and their relation with the environment. Prog Oceanogr 49: 565-580.

Pereira JC, Leandroa RA, Petrere M, Nishida T. 2009. Comparing three indices of catch per unit effort using Bayesian geostatistics. Fish Res 100: 200-209.

Silva A, Skagen DW, Uriarte A, et al. 2009. Geographic variability of sardine dynamics in the Iberian Biscay region. ICES J Mar Sci 66: 495-508.

Solanki HU, Mankodi PC, Nayak SR, Somvanshi VS. 2005. Evaluation of remote-sensing-based potential fishing zones (PFZs) forecast methodology. Cont Shelf Res 25: 2163-2173.

Cite this article as: Lamas L, Oliveira PB, Pinto JP, Almeida S, Deus R, da Silva AJ, Almeida N. 2017. Fishing areas characterisation using the SIMOcean platform. Aquat. Living Resour. 30: 19 